\title{
The motor response to sequential apomorphine in Parkinsonian fluctuations
}

\author{
Andrew J Hughes, Andrew J Lees, Gerald M Stern
}

\begin{abstract}
Fifteen patients with Parkinson's disease and levodopa-induced motor fluctuations, were studied with repeated injections of apomorphine using two protocols to explore possible changes in the duration of motor response. One involved different interdose intervals; in the other, doses were given when the motor effects induced by the previous dose had just worn off. No significant change in the duration of motor response to sequential subcutaneous apomorphine with either protocol was found. The results suggest that rapid changes in receptor sensitivity during repeated intermittent dopaminergic stimulation do not contribute to the pathogenesis of Parkinsonian motor fluctuations.
\end{abstract}

Fluctuations in motor performance are common in levodopa treated Parkinsonian patients, occurring in more than $50 \%$ of patients after five years of treatment. ${ }^{12}$ Severity and duration of disease, as well as duration of levodopa treatment, are important aetiological factors. Levodopa pharmacokinetics, loss of presynaptic dopaminergic nerve terminals, modification of dopamine receptor sensitivity and changes in non-dopaminergic neurotransmitter systems have all been implicated in the pathogenesis of "on-off" oscillations.

Apomorphine, a potent directly acting D1 and D2 receptor agonist, does not share the peripheral and central pharmacokinetic mechanisms of levodopa and is therefore useful for studying central pharmacodynamic factors. Recent studies have suggested reduction of striatal dopaminergic receptor sensitivity following repeated stimulation by dopamine agonists. ${ }^{3-5}$

To investigate possible changes in receptor sensitivity during repeated stimulation, we have studied the motor response of 15 Parkinsonian patients with motor fluctuations using two different patterns of sequential apomorphine administration.

\section{Patients and methods}

Fifteen patients with idiopathic Parkinson's disease (PD) (nine men, six women, mean age
60, range 41-76) were studied. The mean duration of disease was 14 years (7-23), mean duration of levodopa treatment 11 years (516), mean Hoehn and Yahr score when "off" 4.3 , and the mean duration of motor fluctuations 5.5 years (2-8). On the basis of "on/off" charts and patient histories, 13 patients had complex fluctuations, with a mixture of predictable end of dose "wearing-off" and random motor swings with occasional failure to respond to individual levodopa doses. Two had pure "wearing-off" effects. Six were using intermittent subcutaneous apomorphine and one was using subcutaneous apomorphine via an infusion pump. Fourteen patients were taking levodopa, four bromocriptine and four selegiline. "On" period dyskinesias were present in all patients and "off" period dystonia was present in 11 .

Anti-Parkinsonian medication was discontinued nine to 12 hours before the study and the patients were given domperidone $(20 \mathrm{mg}$ three times per day) for at least three days before testing. The study dose for each patient was determined before the day of testing by a stepwise increase in apomorphine to establish a dose which consistently switched the patient from their "off" state to their usual levodopainduced "on" state for a stable period of at least 20 minutes.

Studies began between 8 and 9 am. Eight patients were given an initial dose of apomorphine followed by two further boluses at two hourly intervals and three more doses at hourly intervals. The seven other patients and one patient who had already participated in the first protocol, were given apomorphine injections timed to the wearing off of the motor effect of the previous dose. In these patients, following the first dose, six subsequent injections were given, each five minutes after the termination of the motor response to the previous dose. In cases when a bolus failed to produce a motor response, the next apomorphine dose was given one hour after the previous injection.

Motor response was assessed by measuring alternate unilateral hand tapping for 30 seconds on digital counters mounted $20 \mathrm{~cm}$ apart, timed walking over a 12 metre distance, or by a modified Webster disability scale ${ }^{6}$ whichever gave the best indication of the patients "on" and "off" state during previous days of testing. The time to onset of motor effect, and the duration of action of each bolus were recorded. Patients were allowed a light breakfast and 
Table Duration and latency of motor response to repeated doses of apomorphine with variable interdose intervals

\begin{tabular}{|c|c|c|c|c|c|c|c|c|c|c|c|c|}
\hline \multirow[b]{2}{*}{ Case } & \multicolumn{2}{|l|}{ First } & \multicolumn{2}{|c|}{2 nd -2 hours } & \multicolumn{2}{|c|}{$3 r d-2$ hours } & \multicolumn{2}{|c|}{4 th -1 hour } & \multicolumn{2}{|c|}{5 th -1 hour } & \multicolumn{2}{|c|}{6 th -1 hour } \\
\hline & Lat & Dur & Lat & Dur & Lat & Dur & Lat & Dur & Lat & Dur & Lat & Dur \\
\hline $\begin{array}{l}1 \\
2 \\
3 \\
4 \\
5 \\
6 \\
7 \\
8\end{array}$ & $\begin{array}{r}11 \\
17 \\
10 \\
9 \\
0 \\
10 \\
10 \\
10\end{array}$ & $\begin{array}{r}31 \\
26 \\
58 \\
66 \\
0 \\
50 \\
50 \\
53\end{array}$ & $\begin{array}{r}10 \\
17 \\
10 \\
12 \\
18 \\
12 \\
10 \\
8\end{array}$ & $\begin{array}{l}50 \\
23 \\
77 \\
78 \\
15 \\
56 \\
48 \\
40\end{array}$ & $\begin{array}{r}8 \\
20 \\
11 \\
15 \\
14 \\
13 \\
10 \\
8\end{array}$ & $\begin{array}{l}12 \\
25 \\
63 \\
45 \\
26 \\
52 \\
60 \\
40\end{array}$ & $\begin{array}{r}5 \\
25 \\
10 \\
18 \\
10 \\
13 \\
15 \\
8\end{array}$ & $\begin{array}{l}45 \\
28 \\
65 \\
37 \\
25 \\
44 \\
50 \\
52\end{array}$ & $\begin{array}{r}5 \\
20 \\
12 \\
10 \\
22 \\
12 \\
10 \\
5\end{array}$ & $\begin{array}{l}35 \\
23 \\
72 \\
60 \\
10 \\
52 \\
53 \\
48\end{array}$ & $\begin{array}{l}10 \\
13 \\
\text { ND } \\
\text { ND } \\
19 \\
\text { ND } \\
8 \\
7\end{array}$ & $\begin{array}{c}33 \\
23 \\
\mathrm{ND} \\
\mathrm{ND} \\
36 \\
\mathrm{ND} \\
107 \\
46\end{array}$ \\
\hline
\end{tabular}

Lat $=$ Latency to onset of motor response.

Dur $=$ Duration of motor response.

ND $=$ Not done.

All values in minutes.

lunch at usual hospital meal times and activity was kept to a minimum during the test period.

Student's $t$ test for paired data was used to compare the duration of action with different interdose intervals and with repeated doses of apomorphine. Correlation coefficients were calculated to assess any possible relationship between the latency and duration of each response throughout the test.

\section{Results}

The mean dose of apomorphine was $3.4 \mathrm{mg}$ (1-5), $52.3 \mu \mathrm{g} / \mathrm{kg}$, being almost identical in the two groups of patients studied. The quality of the "on" state for each individual patient was consistent throughout the test period.

Using the first protocol we found no significant trend in the response duration with
Figure 1 Mean duration of motor response to repeated doses of apomorphine timed to the termination of the motor response to the previous dose.

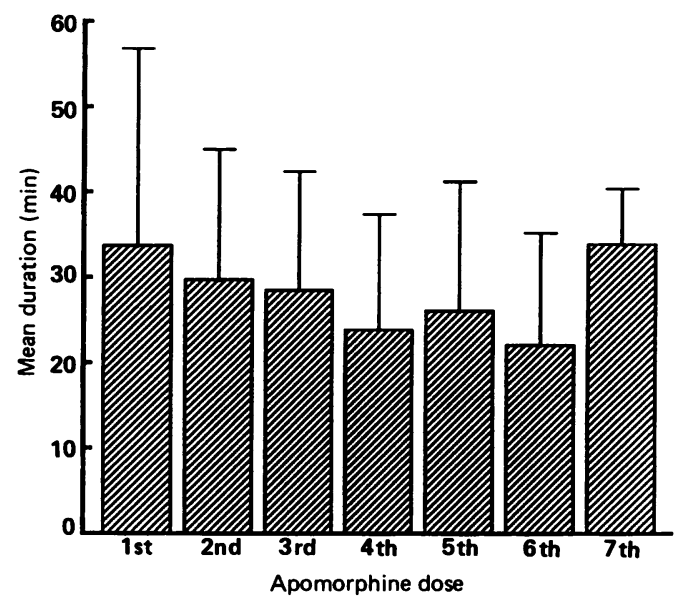

Figure 2 Duration of motor response of individual patients to repeated doses of apomorphine timed to the termination of the motor response to the previous dose. different interdose intervals or with repeated injections at the same interdose interval (table). The variability of response duration differed between patients, some had a large random variation (patients 1 and 5), while others demonstrated a reasonably consistent response (patients 3, 6, 8). Using the second protocol there was again no statistically significant difference in the response duration (figs 1,2). All patients responded to the seventh sequential injection with the mean duration being almost identical to that seen during the first response of the day. There were only three occasions when a dose failed to elicit a motor response.

There was no correlation between the latency to onset of action and the duration of action of each apomorphine bolus.

\section{Discussion}

Although many Parkinsonian patients with motor fluctuations describe a good morning response to levodopa, but a less reliable afternoon response, studies with both levodopa ${ }^{7}$ and apomorphine ${ }^{8}$ have failed to show diurnal changes in receptor sensitivity. Animal studies have shown a progressive reduction in dopaminergic effects with repeated apomorphine administration, ${ }^{9}$ and Obeso et al have recently reported a declining motor response to sequential apomorphine administration in humans, ${ }^{34}$ possibly dependent on the duration of the interdose interval. ${ }^{5}$ In contrast we have found no reduction in motor response duration. There are some methodological differences with our study, in that we used a slightly higher mean dose of apomorphine, $52.3 \mu \mathrm{g} / \mathrm{kg}$ compared with $44.9 \mu \mathrm{g} / \mathrm{kg}^{3}$ and a different time interval between doses. Our experience with apomorphine doses around the threshold level has shown a less reliable response often with complete failure to respond. Available pharmacokinetic studies with apomorphine ${ }^{10}$ suggest that within subject variation in absorption after repeated subcutaneous administration is low. However, the use of near threshold doses may exaggerate the effect of this variable absorption on the duration of motor response, rather than demonstrate declining receptor sensitivity. Although we did not observe any difference in the maintenance of the motor response in the four patients on bromocriptine compared with those on levodopa alone, it is possible that withdrawal of longer acting dopamine agonists may have contributed to the 
declining response seen in previous studies. ${ }^{3}$

Most of our patients had complex fluctuations, following long duration of disease and levodopa treatment. We would expect this group to show a declining response to sequential apomorphine if rapid changes in receptor sensitivity were important in the development of motor fluctuations.

The pathogenesis of motor fluctuations in Parkinson's disease is probably multifactorial, but our results do not support a significant contribution from changes in receptor sensitivity following repetitive dopaminergic stimulation.

AJH was supported by a grant from the United Kingdom Parkinson's Disease Society.

1 Shaw KM, Lees AJ, Stern GM. The impact of treatment of levodopa on Parkinson's disease. $O J$ Med 1980;49: 283-93.
2 Marsden CD, Parkes JD. "On/off” affects in patients with Parkinson's disease on chronic levodopa therapy. Lancet Parkinson's disease on chronic levodopa therapy. Lancet

3 Grandas F, Obeso JA. Motor response following repeated apomorphine administration is reduced in Parkinson's disease. Clin Neuropharmacol 1989;12:14-22.

4 Vaamonde J, Luquin MA, Obeso JA. Levodopa consumption reduces dopaminergic receptor responsiveness in Parkinson's disease. Clin Neuropharmacol 1989;12: 271-84.

5 Grandas F, Obeso JA, Gancher ST, et al. Response to apomorphine in Parkinson's disease depends on the time interval between doses. Neurology 1989;39(Supp 1):365.

6 Kempster PA, Frankel JP, Bovington M, Webster A, Lees AJ, Stern GM. Levodopa peripheral pharmacokinetics Neurol Neurosurg Psychiatry 1989;52:718-23.

7 Frankel JP, Pirtosek Z, Kempster PA, et al. Diurnal responsiveness to oral levodopa. J Neurol Neurosurg responsiveness to oral

8 Gancher ST, Nutt JG, Diurnal responsiveness to apomorphine. Neurology 1987;37:1250-3.

9 Castro R, Abreu P, Calzadilla CH, Rodriguez M. Increased or decreased locomotor response in rats following repeated administration of apomorphine depends on dosage interval. Psychopharmacology 1986;85:333-9.

10 Gancher ST, Woodward WR, Boucher B, Nutt JG. Peripheral pharmacokinetics of apomorphine in humans. $A n n$ Neurol 1989;26:232-8. 